\title{
Tejidos mediáticos de lo negro. Hacia una topografía racializada de la nación colombiana
}

\author{
Catalina Zapata Cortés \\ Bogotá: Editorial Pontificia Universidad Javeriana \\ 2018
}

Juan Carlos Zuluaga

Mg. En Investigación en Ciencias Sociales (UBA).

Profesor del Departamento de Antropología y Sociología - Universidad de Caldas.

$\square$ juanc.zuluaga@ucaldas.edu.co

(10) ORCID: 0000-0002-8015-3044

$\approx$ Google Scholar

Catalina Zapata, historiadora y magister magíster en Sociología de la Cultura y Análisis Cultural, presenta en este libro su más reciente trabajo de investigación sobre los regímenes de representación de la negridad en la nación colombiana. El texto explora de manera diferencial los universos de sentido y las formas de representación de lo 'negro' en un conjunto de imágenes y discursos mediáticos en los que, a pesar de ser asumidos como auténticos de la cultura popular e incluso como reivindicativos de lo negro, un examen en profundidad devela para la autora una gramática colonial, eurocéntrica y racializada.

Teniendo como base conceptual las teorías decolonial y poscolonial (Lugones, Spivak, Bhabha), así como aportes significativos del enfoque de género y de los estudios culturales, especialmente los desarrollos de Rita Segato y Stuart Hall sobre las identidades negras, la autora desarrolla un interesante análisis del orden social racializado de la nación colombiana. Tomando algunos ejemplos de producción gráfica y audiovisual, muestra un juego de ambivalencias, ficciones, máscaras, ocultamientos y manifestaciones explícitas de estereotipos y categorías de identificación, las cuales circulan en los intercambios simbólicos y las interacciones cotidianas en 
el marco de una 'geografía moral racializada' (Wade), conflictiva, ambigua y diferenciada según los contextos de enunciación y las regiones del país. Es importante resaltar que dicho análisis no se limita a la contingencia del presente sino que tiene como telón de fondo los procesos históricos de asimilación, mestizaje y blanqueamiento expresados en los regímenes discursivos y de representación liderados por las élites en el territorio colombiano a partir del siglo XIX.

En el capítulo uno, "El profesor súper O y la pedagogía del castellano. Muchos colombianos / pocos bien hablados", Zapata toma como unidad observacional una miniserie de dibujos animados de amplia difusión a través de un canal de la televisión pública nacional: el Profesor Súper O. El objetivo manifiesto del producto audiovisual consiste en enseñar a niños y adultos el buen uso del idioma español, al tiempo que procura aparentemente la reivindicación y exaltación tanto de una región, el departamento de Chocó, como de las personas afro y algunos elementos de su producción cultural.

Para un observador desprevenido, El Profesor Súper O es el equivalente paródico, autóctono, de los súper héroes clásicos de la segunda mitad del siglo XX en la industria cultural norteamericana; contiene algunos de los elementos tradicionales referidos a la ascendencia extramundana, un alter ego (Charles Ocoró), traje y capa, vehículos especiales (mojarreta, rayamóvil, pulpocreta, etc.), además de una acompañante de aventuras, la Cevichica (Silveria Lucumí), quien en la 〈vida real〉 oficia como cocinera del restaurante del profesor Ocoró. Juntos emprenden aventuras cumpliendo la misión de combatir la ignorancia idiomática y, en temporadas posteriores, conocer los pormenores del proceso de independencia nacional. El análisis estructural y simbólico propuesto por Zapata da cuenta de: i) una concepción racializada del territorio nacional; ii) una visión homogénea, discriminatoria y simplista del Pacífico colombiano y de sus habitantes y iii) una articulación histórica con el pasado colonial y con las ideologías nacionalistas de blanqueamiento del siglo XIX.

Si bien el universo ficcional del Profesor Súper O se presenta en el marco histórico contemporáneo, donde resaltan las nociones de diversidad cultural y el respeto por la diferencia, Catalina Zapata encuentra en él rasgos de una ideología racial y elitista de herencia colonial. En primera instancia señala cómo en los procesos de configuración del territorio nacional, las regiones se erigieron como escenario de diferenciación y jerarquización en el que categorías binarias de civilización/barbarie, blanco/negro, fueron parte de una matriz eurocéntrica a partir de la cual se clasificaron los territorios y sus gentes como más o menos desarrollados 
o 'primitivos' y como más o menos blancos/mestizos o negros. Así, mientras la zona andina en el imaginario nacional se identifica aún hoy con lo blanco/mestizo y con las ideas de progreso, territorios de la costa Caribe y especialmente del Pacífico colombiano han sido identificadas con lo negro, lo selvático y, en general, con la barbarie. Estas representaciones tienen su correlato en los regímenes discursivos hegemónicos sobre los cuales se soportó la construcción de nación en la segunda mitad del siglo XIX, asociados con el carácter hispánico-blanco de las élites y su anhelo de refinamiento idiomático como marcadores que las distanciaba de un "pueblo considerado pobre, ignorante y en su mayoría no blanco" (p. 29). De tal forma, el saber letrado y el hablar 'correctamente' castellano constituyeron signos de distinción que abrían o cerraban puertas de acceso al poder y señalaban la pertenencia o no a la comunidad católica, blanca y humanista.

El Profesor Súper O muestra una aparente contradicción por su pertenencia étnico-racial a comunidades y regiones históricamente asociadas con ideales opuestos a la civilización, pero a la vez encarna el léxico, las actitudes y las maneras valoradas positivamente como parte constitutiva de la sociedad blanca/clasista/progresista del interior del país. Este espacio ambivalente de significado en el que se inscribe el personaje da cuenta de la ideología de blanqueamiento dentro del marco de una geografía racializada de la nación, donde lo negro "puede ser aceptado al tiempo que es considerado inferior y discriminado" (p. 32).

El caso de la Cevichica es quizás donde se muestra un mayor acento en la interseccionalidad de los vectores discriminatorios (sexismo, racismo, clasismo, regionalismo). Silveria Lucumí es quien representa la actualización de la imaginería que sobre el Pacífico se gestó desde el siglo XIX, al exagerar y ridiculizar algunos rasgos de las personas afro. En su figura se destaca su nariz chata, sus labios extragruesos, grandes pechos y glúteos, entre otros atributos, los cuales reproducen una imagen estereotipada y homogeneizada de las gentes de la región, lejos de lo que serían los ideales de belleza dominante. Sus maneras y su forma de hablar chillona y escandalosa, la acercan a lo que sería una mujer "inculta", rústica, fiel modelo del imaginario hegemónico de lo popular. De otro lado, el oficio que desempeña es una marca de bajo estatus con la que históricamente se ha signado a las mujeres negras en buena parte del territorio nacional. Todas estas marcaciones de los personajes condensan un imaginario construido desde el interior del país altamente estigmatizante de lo negro, al tiempo que representa una realidad deformada, descontextualizada y en ocasiones romantizada de la región y de los habitantes del Pacífico colombiano. 
El segundo capítulo, "La Negra Nieves, ¿un personaje 'típicamente vallecaucano'?", presenta una reflexión crítica de la construcción imaginaria de lo negro en un contexto regional, a partir del análisis de una de las caricaturas más icónicas del suroccidente del país, la cual ha alcanzado cierto reconocimiento nacional: La Negra Nieves. Al igual que en el capítulo precedente, Zapata realiza una exploración de los significados explícitos y de aquellos que pasan desapercibidos por la mayor parte de la gente, así como de los espacios de ambivalencia y naturalización del orden social racializado, todo esto en el marco de procesos históricos particulares y las relaciones interétnicas en el Valle del Cauca a partir del siglo XX.

La caricatura de Nieves se publicó por primera vez en 1968 en el diario El País de Cali, y desde entonces se ha mantenido vigente no solo en dicho periódico sino en otras publicaciones de circulación nacional. Tanto la caricatura como su autora, Consuelo Lago, han obtenido premios y reconocimientos entre los que destaca el premio Nacional de Periodismo Simón Bolívar (1983) y del Círculo de Periodistas de Cali (1982), además de ser objeto de exposiciones y compilaciones, e incluso se le dedicó una edición especial en la publicación académica América Negra, con la cual se posicionó como fiel representante de la población afrodescendiente del país. No obstante, la caricatura no ha estado exenta de críticas y reclamos por parte de algunos académicos y representantes de organizaciones sociales, quienes llegaron a presentar una acción de tutela por considerar que es una manifestación más del racismo estructural naturalizado en la sociedad colombiana.

A partir de la revisión histórica de la publicación de la caricatura, así como de los discursos producidos por defensores y adversarios de la misma, Catalina Zapata intenta dar cuenta tanto de los estereotipos explícitos en el personaje como de los espacios de ambivalencia en los que la Negra Nieves adquiere legitimidad por parte algunas personas o rechazo social por parte de otras. De otro lado, la autora reflexiona sobre el contexto particular en el que se inscribe la producción visual, desde las condiciones sociales de origen y las influencias de la creadora (élite caleña) hasta el contexto sociocultural de aparición y su régimen de representación.

Conforme lo muestra Zapata, la Negra Nieves representa un imaginario de mujer negra. En la caricatura se acentúa la intensidad del color $\mathrm{y}$, al igual que sucede con la Cevichica, algunos de los rasgos raciales son exagerados y enfatizados, aunque en el caso de Nieves se trata de una chica muy delgada, inoportuna y de mente rebelde. Su aspecto físico se fue embarneciendo un poco en el tiempo, y a raíz de la tutela pasó 
de representar una empleada doméstica a convertirse en estudiante universitaria. Sin embargo, su origen social y pertenencia racial, su lógica de pensamiento, sus actitudes y formas léxicas se han mantenido prácticamente idénticas desde el momento de su primera publicación. De tal forma, señala la autora que los rasgos racializados continúan siendo el foco productor de sentido de la caricatura, seguido de su condición de clase, claramente inscrita en el marco sociocultural estereotipado de lo que algunos denominan "sectores populares", en este caso, racialmente diferenciados.

Entre las conclusiones del análisis que realiza Zapata destacamos: i) la importancia del lenguaje como campo de diferenciación: la forma de hablar del personaje lo ridiculiza y lo vincula con contextos de precariedad, pobreza y falta de educación. ii) La aceptación de Nieves por parte del público tiene que ver con la capacidad de representar la cultura popular: un imaginario de cultura popular romántico (subalternizante) y paternalista (inferiorizante), donde se destaca justamente la antítesis de lo que las élites blancas se representan para ellas mismas, la irracionalidad, lo instintivo, lo sencillo, lo 'vulgar'. iii) La Negra Nieves, antes que reivindicar las culturas negras, da cuenta de un conjunto de atributos subalternizantes construidos históricamente dentro del sistema de relaciones interraciales en el territorio vallecaucano.

El último capítulo del libro, quizás el más interesante, titula "Del prestigio blanco al exotismo negro. A propósito de la polémica entre el 'Beverly Hills caleño' y el 'Beverly Hills cundiboyacense". En este apartado la autora explora analíticamente la polémica suscitada a partir de la publicación de dos imágenes contrastantes, una en la revista ¡Hola! y otra, que se dio como respuesta a la primera, en la revista SoHo. Las fotografías dan cuenta de dos regímenes regionales de representación de lo negro suficientemente disímiles, aunque tienen como característica compartida que en ambas el lugar de enunciación corresponde al sujeto blanco.

La fotografía de ¡Hola! sirve de marco a la entrevista realizada a la empresaria Rosa Jaluf de Castro en la mansión de su hija, ubicada en un selecto sector al sur de la ciudad de Cali. En el primer plano de la imagen se aprecia a la entrevistada junto a la descendencia femenina de la familia (hija, nieta, biznieta), sentadas con poses sobrias y elegantes en una amplia terraza panorámica con vista a la ciudad. A sus espaldas, una frente a otra, aparecen las imágenes de dos mujeres negras con uniforme de servicio doméstico, llevando entre sus manos sendas bandejas de plata en actitud servil. La fotografía, datada en noviembre de 2011, desató todo tipo de 
críticas y fue comidilla de los medios de comunicación, principalmente del centro del país, que se refirieron en términos desobligantes al grupo familiar y, por extensión, a la élite caleña, acusándolos de un racismo retrógrado y alienante.

Catalina Zapata explora el trasfondo del asunto desde distintas aristas. Basándose en presupuestos bourdianos hace una reflexión histórica sobre el efecto simbólico de los signos de riqueza, estatus y 'buen gusto' identificados en la escena, mostrando ese carácter estilizado y sobrio de las élites burguesas, específicamente de las élites en el territorio vallecaucano, donde las dinámicas interraciales han configurado procesos de diferenciación, exclusión y segregación racial. Luego examina los argumentos de la crítica, encontrando y encuentra dos posiciones al respecto: una que señala a la élite vallecaucana como atrasada y racista; y otra en la que se identifica al conjunto de la sociedad colombiana como elitista y clasista. Vale decir que ambas orientaciones comparten una matriz colonial eurocéntrica basada en los dos ejes de poder mundial, la raza y la relaciones capital-trabajo, materializándose en el territorio nacional en una "racialización de las relaciones de clase" (p. 106). Sin embargo, para la autora, el análisis de los argumentos publicados sobre el asunto en distintos foros mediáticos muestra que la creencia en la democracia racial y el mestizaje hace que en Colombia se considere el racismo como un problema menor, comparado con la discriminación de clase, coadyuvando esto a la invisibilidad política de las poblaciones negras.

Unos meses después de la aparición de la cuestionada fotografía, SoHo quiso desagraviar a la población negra al publicar un reportaje a cuatro mujeres afro de amplio reconocimiento nacional en el campo del modelaje (Vanessa Parra, Belky Arizala, Diana Mina y Yésica Montoya). Dicho reportaje, titulado Elogio de la Mujer Negra, estuvo acompañado por una imagen paródica de aquella que publicara $i$ Hola! Conforme con el estilo de la revista y teniendo en cuenta el público al que se dirige (hombres de clases medias altas), las mujeres afro posan desnudas en una lujosa terraza con piscina y un ambiente selvático de fondo. Al igual que en la foto anterior, tras las modelos aparecen dos mujeres, en este caso mestizas con rasgos indígenas, vestidas con uniforme de servicio doméstico y en la misma actitud servil.

La idea de SoHo apuntaba supuestamente a fungir de antagonista y a revertir la imagen racista de la publicación española (iHola!), mostrando quizás que las mujeres afro también se destacan en el escenario nacional, pueden alcanzar posiciones de poder y ser atendidas por personas "no negras". Sin embargo, a pesar del efecto visual que a primera vista produce 
la fotografía en cuanto a contraste racial, la exploración detallada de la escena que realiza Zapata devela un trasfondo igualmente racista y clasista, además de una mirada sexoracializada de la mujer negra, cuyo lugar de enunciación está dado por el sujeto blanco capitalino, desde el cual se pretende ejercer la autoridad moral sobre otras regiones, en este caso sobre las élites vallecaucanas blancas, a las cuales implícitamente acusa de racistas a través de la representación paródica de su publicación.

Sintetizando el análisis de Zapata, diremos que en ambas fotografías se naturaliza la dominación de clase y el servilismo (ambas escenas tienen servicio doméstico uniformado), presentándolo además como un valor positivo en términos de poder y estatus. En términos raciales, la inversión propuesta por la imagen de SoHo no es tal, pues las mujeres del servicio doméstico de su fotografía no se identifican con una identidad racial blanca semejante a las de la élite vallecaucana exhibida en ¡Hola!, sino que remiten a corporalidades ligadas a lo indígena/mestizo y con atributos lejanos a la estilización que muestran las mujeres de la fotografía a la cual intenta parodiar. En tal sentido, la distinción de clase se mantiene idéntica en los dos referentes, guardando también distancias socio-raciales en la asignación de roles estereotipados según la región que sirva de marco contextual: la subalternización de lo negro en el Valle del Cauca y de lo indígena en la región cundiboyacense. Por último, en cuanto a las protagonistas de la escena, mientras las mujeres de la oligarquía vallecaucana se muestran elegantes y con cierto aire de intelectualidad, las modelos negras posan desnudas y, al igual que las empleadas domésticas, parecen destinadas a trabajar con sus cuerpos, "configurando corporalidades que se ubican en el lado opuesto -oscuro- de un modelo y unos valores reservados a una feminidad blanca-burguesa" (pp. 119-120).

El texto de Catalina Zapata nos recuerda una de las premisas de Bourdieu, según la cual las clases dominantes solo pueden imponerse plenamente en el plano económico cuando logran hegemonizar el campo cultural. Es así como en los distintos ejemplos analizados por la autora se visualiza la forma en la que operan vectores discriminatorios subalternizantes, de manera interconectada, a veces ambivalentes, a veces ocultos y en ocasiones totalmente manifiestos en los regímenes de representación, a través de los cuales, como señala Stuart Hall, se construyen las identidades. De otro lado, el libro de Zapata ayuda a pensar sobre la capacidad que tienen los medios de comunicación para producir representación y significado; además, constituye un aporte "hacia una topografía racializada de la nación colombiana". 